\title{
Evaluation and Analysis of Variance of Storage Stability of Asphalt Binder Modified by Nanotitanium Dioxide
}

\author{
Xiaolong Zou, ${ }^{1,2,3}$ Aimin Sha, ${ }^{2}$ Biao Ding, ${ }^{4}$ Yuqiao Tan, ${ }^{2}$ and Xiaonan Huang ${ }^{2}$ \\ ${ }^{1}$ School of Architecture and Civil Engineering, Xian University of Science and Technology, Xian, Shaanxi, China \\ ${ }^{2}$ Key Laboratory for Special Area Highway Engineering of Ministry of Education, Chang'an University, Xian, Shaanxi, China \\ ${ }^{3}$ Guangxi Key Lab of Road Structure and Materials, Guangxi Transportation Research \& Consulting Co., Ltd., \\ Nanning, Guangxi, China \\ ${ }^{4}$ CCCC First Highway Consultants Co., Ltd., Xian, Shaanxi, China
}

Correspondence should be addressed to Xiaolong Zou; zouxiaolong_1234@163.com

Received 6 April 2017; Revised 21 June 2017; Accepted 15 August 2017; Published 10 October 2017

Academic Editor: Qingli Dai

Copyright (C) 2017 Xiaolong Zou et al. This is an open access article distributed under the Creative Commons Attribution License, which permits unrestricted use, distribution, and reproduction in any medium, provided the original work is properly cited.

To investigate the effects of nanoparticle content, storage time, and storage temperature on the storage stability of asphalt binders modified by nanoparticles, hot tube storage tests, softening point tests, and dynamic-shearing rheometer (DSR) tests were adopted to evaluate the properties of two kinds of nanotitanium dioxide $\left(\mathrm{TiO}_{2}\right)$ modified asphalt binders. A statistical one-way analysis of variance (ANOVA) test was employed to analyze the effects of those variations on the storage stability of the nano-TiO ${ }_{2}$ modified asphalt binders. The results indicated that the softening point, the failure temperature, the dynamic-shear viscosity, and $\left|G^{*}\right| / \sin (\delta)$ of the binders increased with nanoparticle content. The storage stability of the binders decreased with nanoparticle content. The impact of storage time on the storage stability of the binders was remarkable when the storage time was more than $48 \mathrm{~h}$. Moreover, the storage stability of the binders at low temperatures was better than that at high temperatures. Based on the one-way ANOVA, the size of nanoparticle had little influence on the storage stability of the nano- $\mathrm{TiO}_{2}$ modified asphalt binders in this study. Reducing the nanoparticle size cannot effectively enhance the storage stability of the nanoparticle modified asphalt binder due to the agglomeration of nanoparticle.

\section{Introduction}

Nanomaterials have application in asphalt mixtures with increase of performance requirement of pavement [1]. The one dimension of nanomaterials is usually less than $100 \mathrm{~nm}$ which has a larger surface area-to-volume ratio than that of conventional materials, so that nanomaterials have some special properties to improve the performance of asphalt mixture [2]. The nanomaterials using in asphalt construction include nanoclay, nano- $\mathrm{SiO}_{2}$, and nanotitanium dioxide $\left(\mathrm{TiO}_{2}\right)$ $[3,4]$.

Nanoclay has a good compatibility with asphalt because of its special composite. The addition of nanoclay into asphalt is useful to improve the short- and long-term aging resistance of the modified asphalt binder. At the same time, it contributes to the physical, mechanical, and rheological properties of modified asphalt binder [5-9]. In addition, nanoclay can improve the rutting resistance of styrene-butadienestyrene (SBS) modified asphalt binder [10].

Nano- $\mathrm{SiO}_{2}$ also is added to an SBS modified asphalt binder in order to improve the performance of asphalt mixture. The research of Mojtaba et al. shows that the asphalt mixture using asphalt binder modified by nano- $\mathrm{SiO}_{2}$ and SBS has better performance than the asphalt mixture using unmodified asphalt binder [11].

$\mathrm{TiO}_{2}$ has the special crystal structure which can absorb or catalytic decomposition part of automobile exhaust; thus it can be applied in road construction and play a significant role in promoting for environmental protection [12]. Due to the increasing awareness of environmental protection, more and more attention has been paid to the environmentfriendly roads. With the continuous increase in the number of car ownerships, automobile exhaust is one of the main 


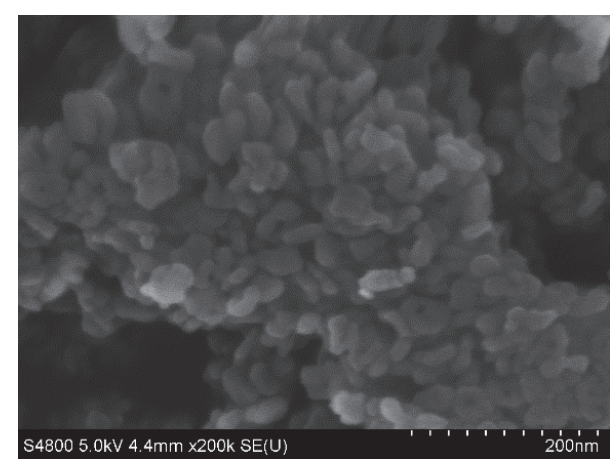

(a) $\mathrm{TiO}_{2}-50$

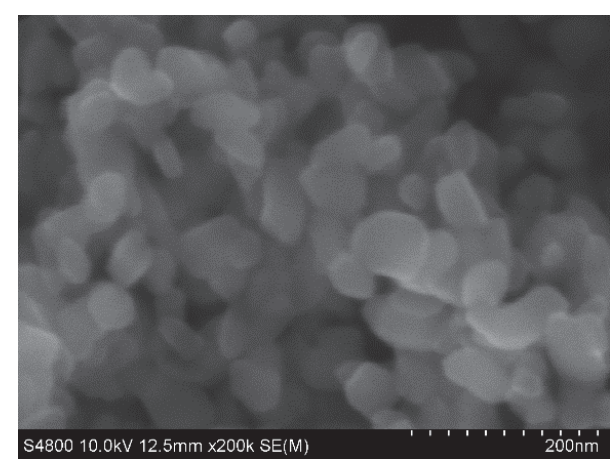

(b) $\mathrm{TiO}_{2}-100$

FIGURE 1: Electron microscope scanning images.

sources of pollution [13]. The study of $\mathrm{TiO}_{2}$ use in construction of pavement has gradually become a hot topic. Researchers in Japan, China, Italy, and France tried the photocatalytic decomposition of $\mathrm{TiO}_{2}$ in the construction of roads [14].

Nano- $\mathrm{TiO}_{2}$ has the advantages in both photocatalytic decomposition and the scale effect, so that nano- $\mathrm{TiO}_{2}$ attracted the attention. In addition, nano- $\mathrm{TiO}_{2}$ has a good shielding effect on ultraviolet (UV) light, which can be used as a UV absorbent to mitigate UV aging of asphalt $[15,16]$. Xiao and $\mathrm{Li}$ evaluated the performance of the mixture used nano- $\mathrm{TiO}_{2}$ as a modifier in SBS modified asphalt binder. Their research showed that the mixture using nano- $\mathrm{TiO}_{2}$ and SBS composite modified asphalt binder had better hightemperature stability, water stability, and low temperature cracking resistance than those of the mixture using unmodified asphalt binder [17]. Hassan et al. studied the UV aging resistance of nano- $\mathrm{TiO}_{2}$ modified asphalt binder. Nano-TiO modified asphalt binder had the lower penetration loss rate, the lower softening point increase, and the lower ductility loss rate after UV aging than those of the ordinary asphalt binder, which indicated that nano- $\mathrm{TiO}_{2}$ improved the UV aging resistance of asphalt binder [18].

Those studies mainly focus on the effects of nanoparticles on the performance of the modified asphalt binders; however, there is still a lack of research on the effects of nanoparticles on the storage stability of modified asphalt binders.

When a modifier is added to asphalt binder, the variation in the storage stability of the binder should be changed [19]. Moreover, the storage stability could have an influence on the physical parameters of asphalt binder, such as density, softening point, viscosity, and rheological properties [20].

Because the nano- $\mathrm{TiO}_{2}$ has large surface area and high surface free energy, the agglomeration phenomenon is easy to occur. Deepening the understanding of the influences of the storage stability on the properties of asphalt binder is helpful to take corresponding measures to improve the storage stability, so it is necessary to study the storage stability of the nano- $\mathrm{TiO}_{2}$ modified asphalt. This study adopted hot tube storage test, softening point test, and dynamic-shearing rheometer (DSR) test to investigate the storage stability of
TABLE 1: Physical properties and chemical components of the base asphalt.

\begin{tabular}{lcc}
\hline Items & Test results & Test specification \\
\hline Softening point $\left({ }^{\circ} \mathrm{C}\right)$ & 43.9 & ASTM D36 \\
\hline Ductility $\left(15^{\circ} \mathrm{C}\right)(\mathrm{cm})$ & $>150$ & ASTM D113 \\
\hline Penetration $\left(25^{\circ} \mathrm{C}\right)(0.1 \mathrm{~mm})$ & 103 & ASTM D5 \\
\hline Saturates $(\%)$ & 31 & \\
Aromatics $(\%)$ & 40 & ASTM D4124 \\
Resins $(\%)$ & 22 & \\
Asphaltene $(\%)$ & 7 & \\
\hline
\end{tabular}

TABLE 2: Characteristics of nano- $\mathrm{TiO}_{2}$.

\begin{tabular}{lcc}
\hline Items & $\mathrm{TiO}_{2}-50$ & $\mathrm{TiO}_{2}-100$ \\
\hline Crystal type & Anatase & Anatase \\
Average particle size $(\mathrm{nm})$ & 50 & 100 \\
Purity $(\%)$ & 99.8 & 99.5 \\
Color & White & White \\
\hline
\end{tabular}

the nano- $\mathrm{TiO}_{2}$ modified asphalt binders with the variation of nanoparticle content, storage time, and storage temperature.

\section{Materials and Test Methods}

\subsection{Materials and Sample Preparation}

2.1.1. Materials. A base asphalt was used in this research, which was produced by Karamay Petrochemical Company, China. The physical and chemical parameters of the base asphalt are shown in Table 1.

Two types of nano- $\mathrm{TiO}_{2}$ from Nanjing Emperor Nano Material Co., Ltd., China, were selected for this investigation: the one with the average particle size of $50 \mathrm{~nm}$ was named $\mathrm{TiO}_{2}-50$ and the other with the average particle size of $100 \mathrm{~nm}$ was named $\mathrm{TiO}_{2}-100$. The characteristics of the two types of nano- $-\mathrm{TiO}_{2}$ are shown in Table 2. The morphology of the nano- $-\mathrm{TiO}_{2}$ was observed by scanning electron microscope (SEM). The images of SEM are shown as Figure 1. From 
Figure 1, according to the scale in the images, the particle of $\mathrm{TiO}_{2}-50$ is pie-shaped with the diameter of about $100 \mathrm{~nm}$ and the particle of $\mathrm{TiO}_{2}-100$ is pie-shaped with the diameter of about $400 \mathrm{~nm}$. In addition, the agglomeration of $\mathrm{TiO}_{2}-50$ is more obvious than that of $\mathrm{TiO}_{2}-100$.

2.1.2. Preparation of Modified Asphalt Binder. The base asphalt was heated to $160^{\circ} \mathrm{C}$ in a small container until it flowed fully, and the temperature was kept constant. A certain amount of nanoparticle material was slowly added and mixed into asphalt under $3000 \mathrm{rpm}$ for $30 \mathrm{~min}$. Mixing was then continued at $160^{\circ} \mathrm{C}$ with $500 \mathrm{rpm}$ for $30 \mathrm{~min}$ and the blend became essentially homogenous. After completion, the homogeneous modified asphalt binders were cooled to room temperature for further testing.

Two series of modified asphalt binders were prepared with the two types of nano- $\mathrm{TiO}_{2}$. The nanoparticle contents used in the tests were $0.50 \%, 1.00 \%, 1.50 \%, 2.00 \%$, and $2.50 \%$ by weight of the corresponding blends. The base asphalt was also tested as a reference.

\subsection{Test Methods}

2.2.1. Hot Tube Storage Test. In order to study effects of nanoparticle content on the storage stability of the modified asphalt binders, two types of modified asphalt binders with nanoparticle contents of $0.50 \%, 1.00 \%, 1.50 \%, 2.00 \%$, and $2.50 \%$ were applied in this study for hot tube storage test according to the conventional procedure [21,22].

The modified asphalt binders were melted in an oven at $163^{\circ} \mathrm{C}$ and then poured into an aluminum foil tube $(25 \mathrm{~mm}$ in diameter and $140 \mathrm{~mm}$ in height). The tubes containing the modified asphalt binders were sealed and stored vertically in an oven at $163^{\circ} \mathrm{C}$ for $48 \mathrm{~h}$. The tubes were removed from the oven and cooled in a freezer at $-20^{\circ} \mathrm{C}$ for $4 \mathrm{~h}$ to solidify the modified asphalt binders completely. The cooled modified asphalt binders were cut transversely into three equal sections. The modified asphalt binders from the top and the bottom sections of the same tube were applied for further softening point tests and dynamic-shear rheometer (DSR) tests.

To study the effects of storage time on the storage stability, the two types of the modified asphalt binders with a nanoparticle content of $2.50 \%$ were applied for hot tube storage test at the storage time of $6,12,24,48,72$, and $120 \mathrm{~h}$ and at storage temperature of $163^{\circ} \mathrm{C}$.

To study the effects of storage time on the storage stability, the two types of modified asphalt binders with a nanoparticle content of $2.50 \%$ were applied for hot tube storage test at the storage time of $48 \mathrm{~h}$ and at storage temperature of $120^{\circ} \mathrm{C}$, $163^{\circ} \mathrm{C}$, and $175^{\circ} \mathrm{C}$.

2.2.2. Softening Point Test. The modified asphalt binders from the top and the bottom sections of the same tube were applied for softening point tests according to the standard test method ASTM D36. The difference of the softening points between the top and the bottom sections of the binders was calculated to evaluate the high-temperature storage stability of the modified asphalt binders.

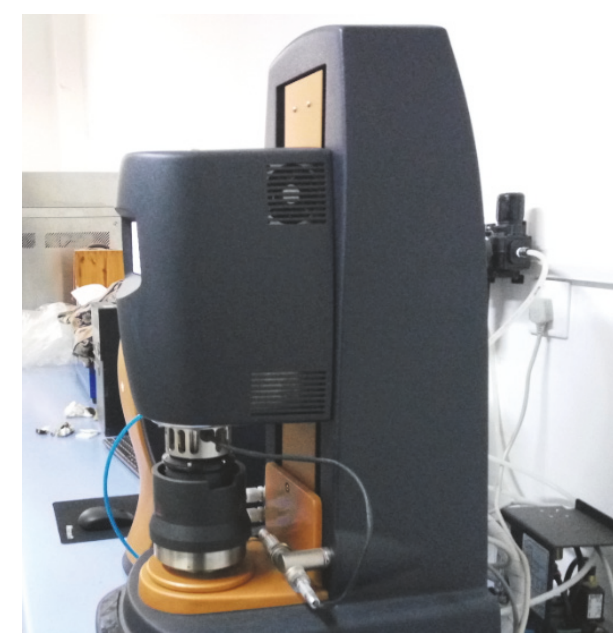

FIGURE 2: The dynamic-shear rheometer.

2.2.3. Dynamic-Shear Rheometer (DSR) Test. The accuracy of softening point test is relatively low, which is hard to evaluate the different of storage stability of modified asphalt binders, especially with low nanoparticle content. However, DSR test has a high accuracy and is commonly used for the fundamental rheological characterization of asphalt binder. Asphalt binder has different rheological characterization due to different composition, so DSR test can be used to investigate the storage stability of asphalt binder.

The DSR test was performed on the binders from the top and the bottom sections of the same tube using a TA rheometer, shown as Figure 2. The test was performed under controlled strain loading conditions using stain $12 \%$ at frequency $10 \mathrm{rad} / \mathrm{s}$ at temperature $58^{\circ} \mathrm{C}$. The test samples were diameter of $25 \mathrm{~mm}$ and thickness of $1000 \mu \mathrm{m}$. Test procedure followed AASHTO standard TP 5.

The viscoelastic properties of the asphalt binder were evaluated by measuring the complex shear modulus $G^{*}$ and phase angle $\delta$. Superpave specification uses rutting factor $G^{*} / \sin (\delta)$ to characterize the high-temperature resistance to permanent deformation of asphalt binder. The principal viscoelastic parameters obtained from the DSR were the magnitude of the complex shear modulus $\left(G^{*}\right)$ and the phase angle $(\delta)$ and $\left|G^{*}\right| / \sin (\delta)$ was calculated. The failure temperature and the dynamic-shear viscosity $\left(\left|n^{*}\right|\right)$ at $135^{\circ} \mathrm{C}$ were determined following the Superpave mix design specifications. $\left|G^{*}\right| / \sin (\delta)$, the failure temperature, and the dynamicshear viscosity were used as indexes to evaluate the storage stability of modified asphalt binders.

\section{Results and Discussion}

3.1. Effects of Nanoparticle Content. To study the effects of nanoparticle content on the storage stability of the nanoparticle modified asphalt binders, the asphalt binder samples with nanoparticle contents of $0.50 \%, 1.00 \%, 1.50 \%, 2.00 \%$, and $2.50 \%$ after hot tube storage tests were applied to investigate the values of softening point, failure temperature, dynamicshear viscosity, and $\left|G^{*}\right| / \sin (\delta)$. 


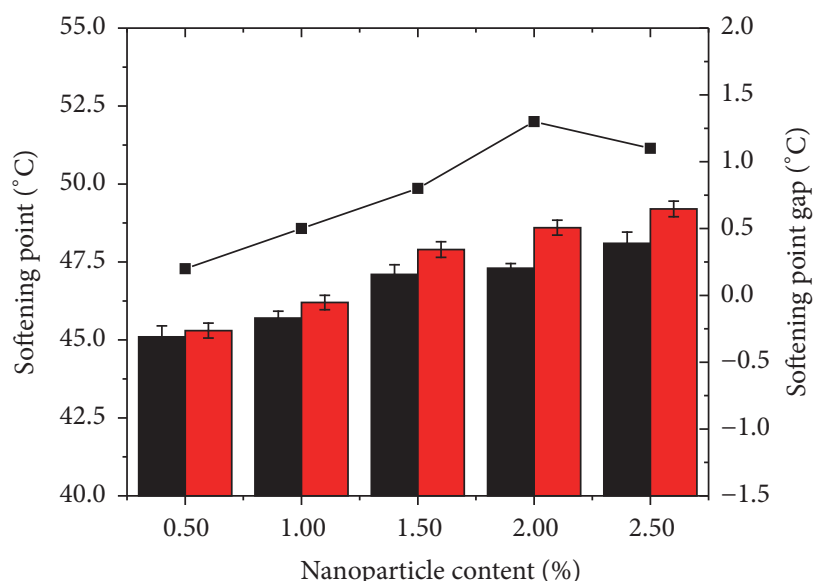

Nanoparticle content (\%)

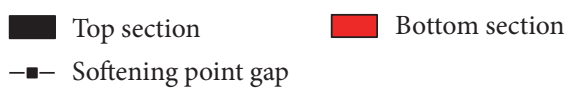

(a) $\mathrm{TiO}_{2}-50$

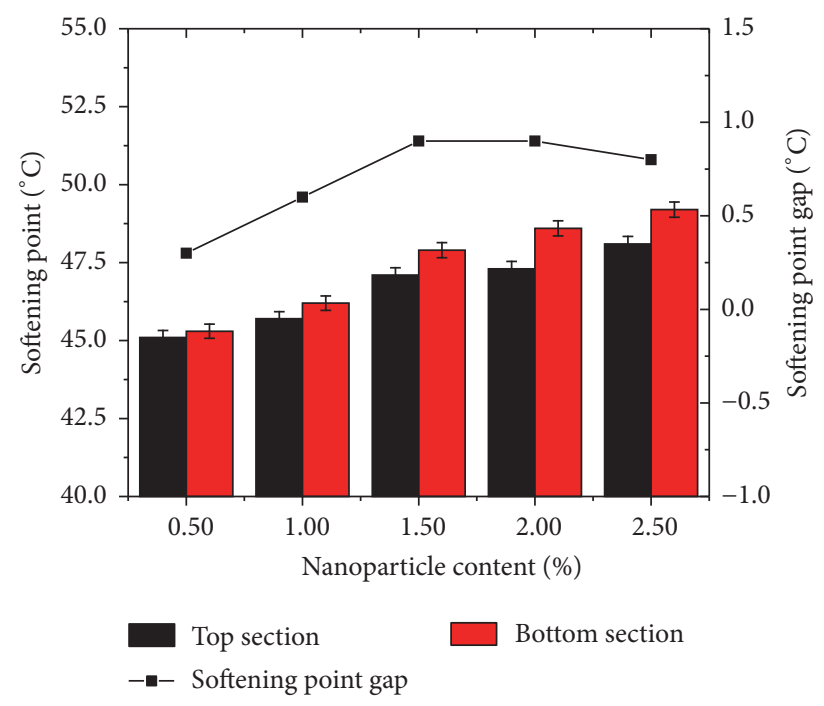

(b) $\mathrm{TiO}_{2}-100$

FIGURE 3: The effects of nanoparticle content on the softening point.

(1) The Effects of Nanoparticle Content on the Softening Point. The results of the softening point test using the two types of asphalt binders modified with different nanoparticle contents were shown as Figure 3. It can be observed that, with the increase of the nanoparticle content, the softening point of the asphalt binders modified by $\mathrm{TiO}_{2}-50$ and $\mathrm{TiO}_{2}-100$ increased gradually. Comparing the differences between the two modified asphalt binders, it can be found that the softening point of $\mathrm{TiO}_{2}-50$ modified asphalt binder was relatively large.

A softening point gap was the difference of the softening point of the nano- $\mathrm{TiO}_{2}$ modified asphalt binders between the top and the bottom sections in the aluminum foil tubes after the hot tube storage test. To evaluate the storage stability of the modified asphalt binders, the softening point gaps under the conditions of different nanoparticle content were calculated and the results are presented in Figure 3. With the increase of the nanoparticle content, the softening point gap of $\mathrm{TiO}_{2}-50$ modified asphalt binder increased gradually and reached the peak at the nanoparticle content of $2.00 \%$. Similarly, the softening point gap of $\mathrm{TiO}_{2}-100$ modified asphalt binder reached the peak at the nanoparticle content of $1.50 \%$ and decreased lightly after that.

It was considered that the dispersion of nanoparticle decreased with the increasing nanoparticle content and the agglomeration became more significant leading to the decrease of the storage stability of modified asphalt binders.

The softening point test is a common test for storage stability of modified asphalt binder. When the difference of the softening points between the top and the bottom sections of the sample treated for $48 \mathrm{~h}$ at $163^{\circ} \mathrm{C}$ was less than $2.5^{\circ} \mathrm{C}$, the sample was considered to have good high-temperature storage stability [2]. Based on this principle, the two types of nano- $\mathrm{TiO}_{2}$ modified asphalt binders had good hightemperature storage stability.

(2) The Effects of Nanoparticle Content on the DynamicShear Viscosity. The effects of nanoparticle content on the dynamic-shear viscosity are shown as Figure 4 . The dynamicshear viscosity of two kinds of modified asphalt binders correspondingly increased with the increasing nanoparticle content, which indicated that the content of nanoparticle affected the dynamic-shear viscosity of asphalt binder modified by $\mathrm{TiO}_{2}-50$ and $\mathrm{TiO}_{2}-100$.

The Krieger-Dougherty equation gives a description of the relationship between the particle volume fraction and the relative viscosity in a monodisperse system $[23,24]$ :

$$
\eta_{r}=\left(1-\frac{\phi}{\phi_{\max }}\right)^{-[\eta] \phi_{\max }}
$$

where $\eta_{r}$ is the relative viscosity, $[\eta]$ is the intrinsic viscosity, $\phi$ is the volume fraction, and $\phi_{\max }$ is the maximum volume fraction of the latex. According to (1), it can be found that the larger the volume fraction, the more the relative viscosity, correspondingly, the higher the nanoparticle content, the more the dynamic-shear viscosity.

The dynamic-shear viscosity gaps under the conditions of different nanoparticle content are shown as Figure 4. For the asphalt binders modified by $\mathrm{TiO}_{2}-50$ and $\mathrm{TiO}_{2}-100$, the dynamic-shear viscosity gap increased as the nanoparticle content increased. The results indicated that the difference of the shear viscosity between the top section and the bottom section in the aluminum foil tube increased with the nanoparticle content.

With the increase of nanoparticle content, the agglomeration of nanoparticle increased due to the effect of large surface energy. Besides, the interaction between the agglomerated nanoparticles and asphaltene molecules by Van der Waals forces transfers the dispersed system of modified asphalt binders from a stable state to a metastable state, attribute to decreasing the storage stability.

(3) The Effects of Nanoparticle Content on the Failure Temperature. Although the softening point test is a common test 


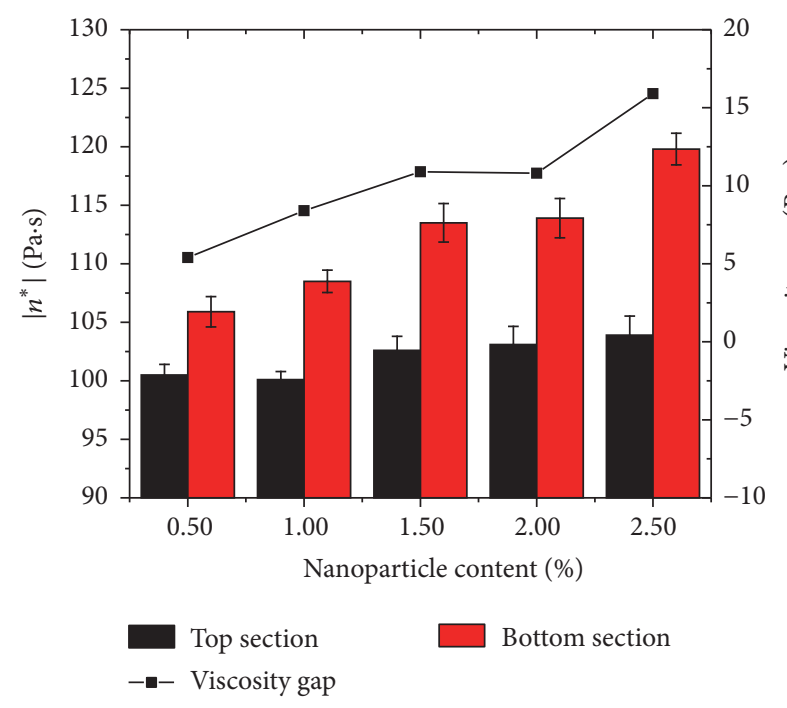

(a) $\mathrm{TiO}_{2}-50$

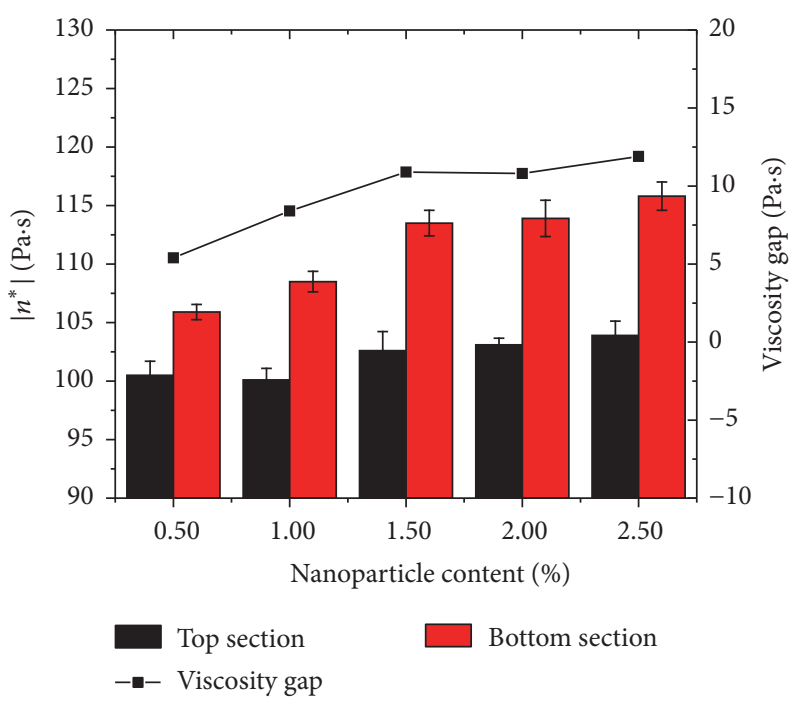

(b) $\mathrm{TiO}_{2}-100$

FIGURE 4: The effects of nanoparticle content on the dynamic-shear viscosity.

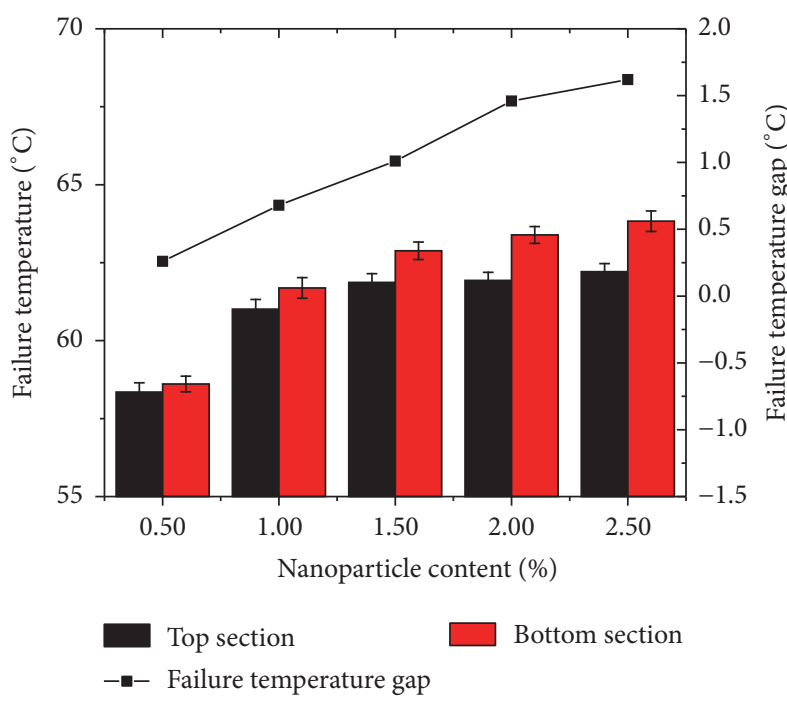

(a) $\mathrm{TiO}_{2}-50$

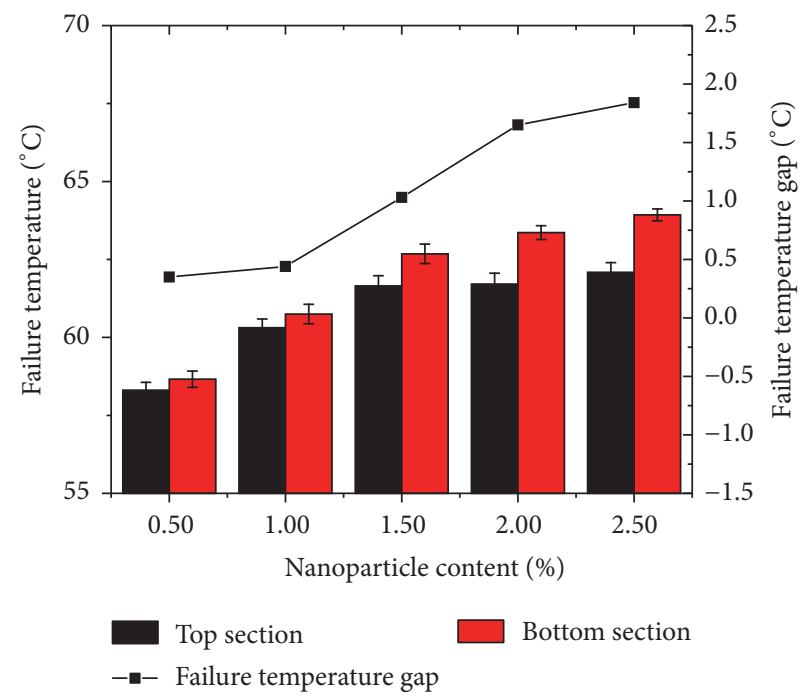

(b) $\mathrm{TiO}_{2}-100$

FIGURE 5: The effects of nanoparticle content on the failure temperature.

method, the accuracy of the test is not high, especially for the modified asphalt with a small amount of nanoparticles. It was necessary to apply a high accuracy test method to investigate the storage stability, so DSR test was applied in this study.

The effects of nanoparticle content on the failure temperature are shown as Figure 5. With the increase of nanoparticle content, the failure temperatures of the asphalt binder modified by $\mathrm{TiO}_{2}-50$ and $\mathrm{TiO}_{2}-100$ presented a continued slight growth. When the nanoparticle content increased from $0.50 \%$ to $2.50 \%$, the failure temperature of $\mathrm{TiO}_{2}-50$ modified asphalt binder increased from $58.35^{\circ} \mathrm{C}$ to $62.21^{\circ} \mathrm{C}$ and that of
$\mathrm{TiO}_{2}-100$ modified asphalt binder increased from $58.31^{\circ} \mathrm{C}$ to $62.09^{\circ} \mathrm{C}$.

Failure temperature gaps under the conditions of different nanoparticle content were also calculated and the results are presented in Figure 5. The failure temperature gap of $\mathrm{TiO}_{2}-50$ modified asphalt binder steadily increased with the nanoparticle content and that of $\mathrm{TiO}_{2}-100$ modified asphalt binder increased slowly before nanoparticle content of $1.00 \%$ and then presented a larger rise.

Overall, the $\mathrm{TiO}_{2}-50$ modified asphalt binder and the $\mathrm{TiO}_{2}-100$ modified asphalt binder had similar change regulation of failure temperature over the nanoparticle content. 

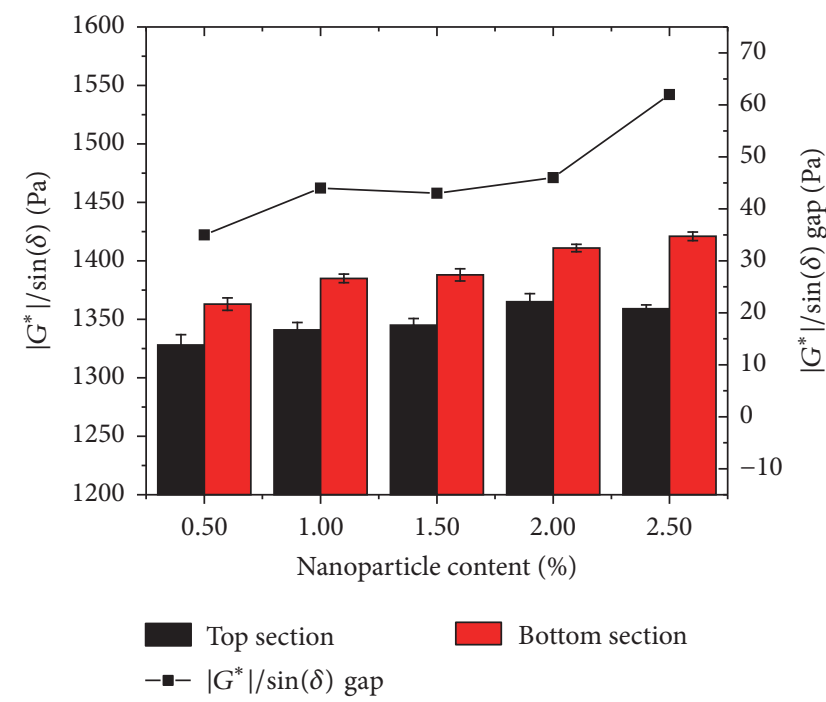

(a) $\mathrm{TiO}_{2}-50$

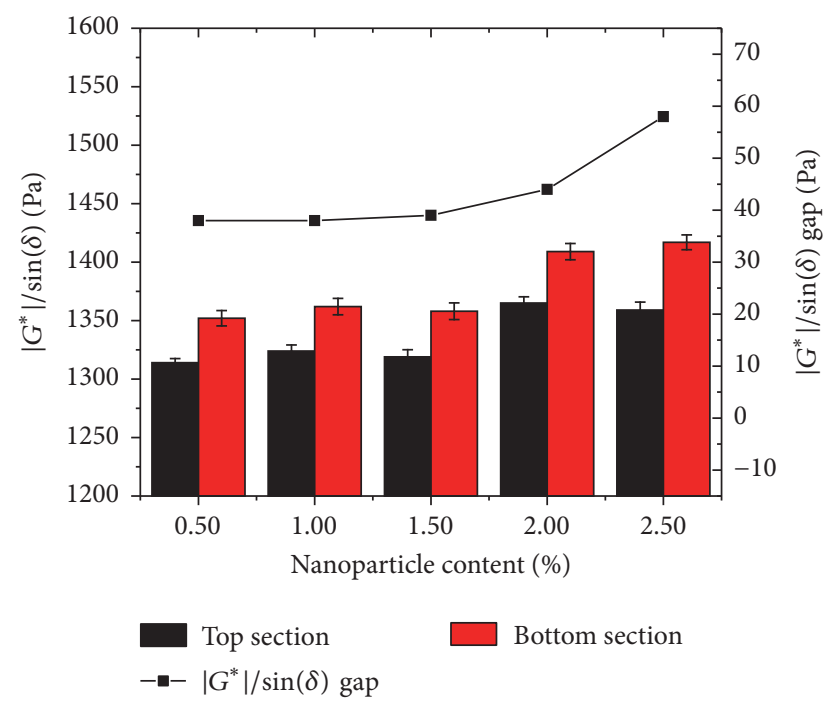

(b) $\mathrm{TiO}_{2}-100$

Figure 6: The effects of nanoparticle content on $\left|G^{*}\right| / \sin (\delta)$.

(4) The Effects of Nanoparticle Content on the Rutting Factor. The effects of nanoparticle content on $\left|G^{*}\right| / \sin (\delta)$ are shown as Figure 6. For the two kinds of modified asphalt binders, $\left|G^{*}\right| / \sin (\delta)$ increased slowly as the nanoparticle content increased.

$\left|G^{*}\right| / \sin (\delta)$ gaps under the conditions of different nanoparticle content were calculated and are presented in Figure 6. According to the curve of the $\left|G^{*}\right| / \sin (\delta)$ gap of $\mathrm{TiO}_{2}-50$ modified asphalt binder, the $\left|G^{*}\right| / \sin (\delta)$ gap increased slowly when the amount of $\mathrm{TiO}_{2}-50$ was less than $2.00 \%$, while the $\left|G^{*}\right| / \sin (\delta)$ gap increased significantly in the amount of $2.50 \%$. By contrast, the $\left|G^{*}\right| / \sin (\delta)$ gap of $\mathrm{TiO}_{2}-100$ modified asphalt binder showed a slow increasing trend in the range of test content of $0.50 \% \sim 2.50 \%$. The results indicated that the nanoparticle content had effects on the $\left|G^{*}\right| / \sin (\delta)$.

In general, the gap of softening point, the gap of failure temperature, the gap of dynamic-shear viscosity, and the gap of $\left|G^{*}\right| / \sin (\delta)$ increased with the nanoparticle content. For the asphalt binders modified by $\mathrm{TiO}_{2}-50$ and $\mathrm{TiO}_{2}-$ 100 , the storage stability of nanoparticle modified asphalt binders decreased with the increase of the nanoparticle content, which could be mainly due to the agglomeration of nanoparticle increased with the increase of nanoparticle content based on the microscale analysis.

3.2. Effects of Storage Time. To study effects of storage time on the storage stability of the nanoparticle modified asphalt binders, the two types of the modified asphalt binder samples with a nanoparticle content of $2.50 \%$ after hot tube storage tests at the storage time of $6,12,24,48,72$, and $120 \mathrm{~h}$ and at storage temperature of $163^{\circ} \mathrm{C}$ were applied to investigate the values of $\left|G^{*}\right| / \sin (\delta)$.

Figure 7 shows the effects of storage time on $\left|G^{*}\right| / \sin (\delta)$. For both $\mathrm{TiO}_{2}-50$ modified asphalt binder and $\mathrm{TiO}_{2}-100$ modified asphalt binder, the values of $\left|G^{*}\right| / \sin (\delta)$ were relatively small at the storage time before 48 hours and dramatically increased after 48 hours.

To analyze the effects of storage time on storage stability of nanoparticle modified asphalt binders, the $\left|G^{*}\right| / \sin (\delta)$ gaps under different conditions of storage time were calculated and are presented in Figure 7. For $\mathrm{TiO}_{2}-50$ modified asphalt binder, the $\left|G^{*}\right| / \sin (\delta)$ gap had a trend of increase with the storage time before 48 hours and changed little after 48 hours. For $\mathrm{TiO}_{2}-100$ modified asphalt binder, the variation of $\left|G^{*}\right| / \sin (\delta)$ gap was like that of $\mathrm{TiO}_{2}-50$. The results indicated that the storage time had an impact on storage stability of nanoparticle modified asphalt binders and the impact was remarkable when the storage time was more than 48 hours. Moreover, it can be found that the $\left|G^{*}\right| / \sin (\delta)$ gap of $\mathrm{TiO}_{2}-50$ at 72 hours and that of $\mathrm{TiO}_{2}-100$ at 120 hours decreased lightly, that it was considered that both of the top and the bottom section of binder specimens were aged heavily, affecting the $\left|G^{*}\right| / \sin (\delta)$ gap when the storage time was more than 48 hours.

Nanoparticles tend toward agglomeration to depress the surface energy based on the lowest energy principle [24]. With increasing storage time, the agglomerated nanoparticles will redisperse or escalate agglomeration resulting in reducing the storage stability of the modified asphalt binders.

3.3. Effects of Storage Temperature. To study the effects of storage time on the storage stability of the nanoparticle modified asphalt binders, the two types of the modified asphalt binder samples with a nanoparticle content of $2.50 \%$ after hot tube storage tests at the storage time of $48 \mathrm{~h}$ and at storage temperature of $120^{\circ} \mathrm{C}, 163^{\circ} \mathrm{C}$, and $175^{\circ} \mathrm{C}$ were applied to investigate the values of $\left|G^{*}\right| / \sin (\delta)$.

Figure 8 shows the effects of storage temperature on $\left|G^{*}\right| / \sin (\delta)$. For both the $\mathrm{TiO}_{2}-50$ modified asphalt binder 


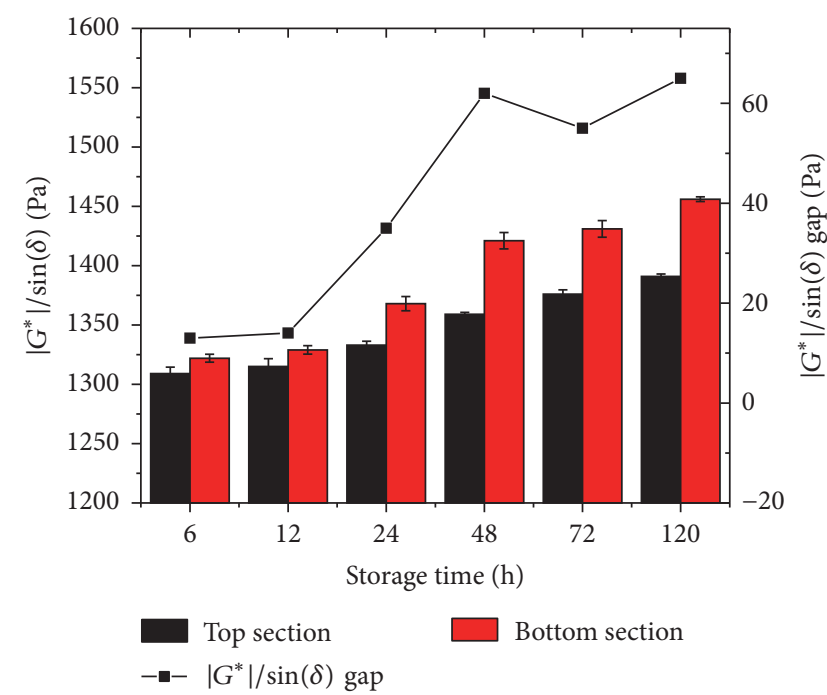

(a) $\mathrm{TiO}_{2}-50$

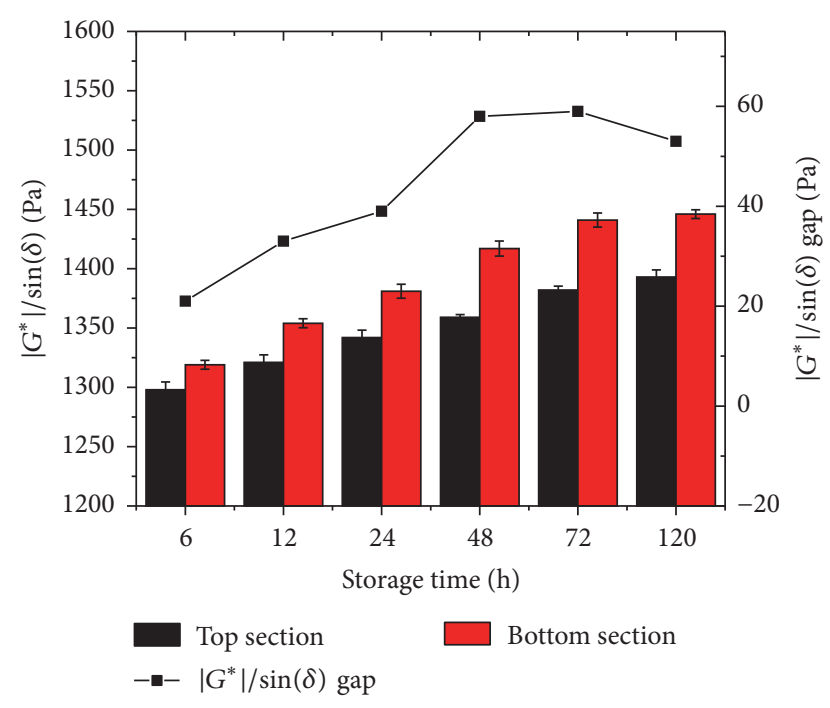

(b) $\mathrm{TiO}_{2}-100$

FIGURE 7: The effects of storage time on $\left|G^{*}\right| / \sin (\delta)$.

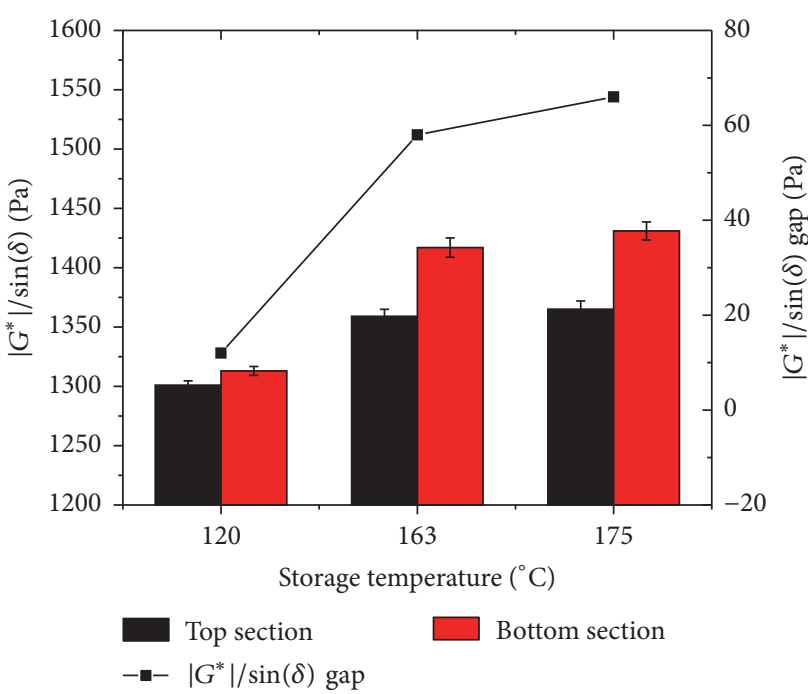

(a) $\mathrm{TiO}_{2}-50$

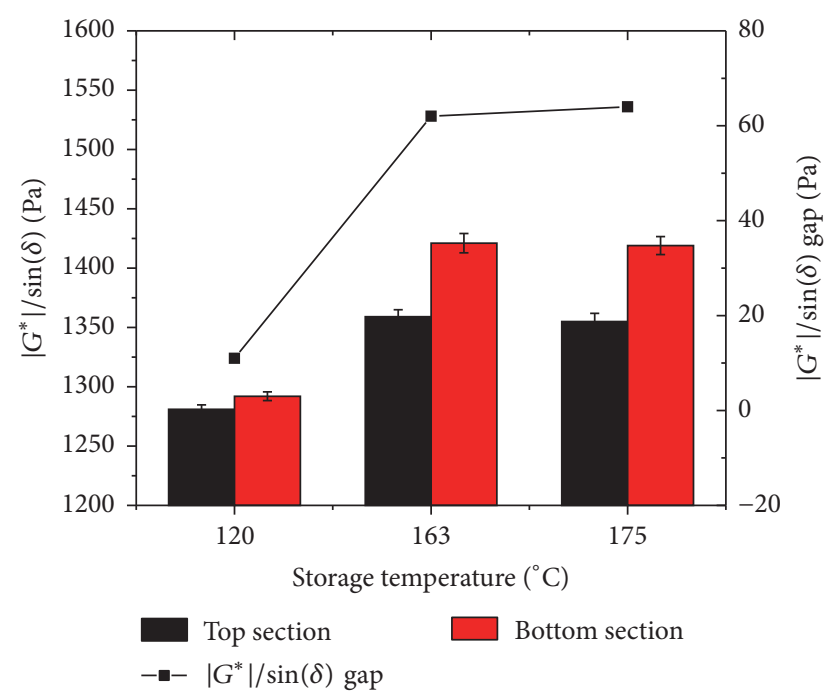

(b) $\mathrm{TiO}_{2}-100$

Figure 8: The effects of storage temperature on $\left|G^{*}\right| / \sin (\delta)$.

and the $\mathrm{TiO}_{2}-100$ modified asphalt binder, $\left|G^{*}\right| / \sin (\delta)$ increased with the storage temperature.

The $\left|G^{*}\right| / \sin (\delta)$ gaps at different storage temperatures were calculated to analyze the effects of storage temperature on the storage stability and the calculation is presented as curves of $\left|G^{*}\right| / \sin (\delta)$ gap in Figure 8. It can be seen from Figure 8 that the two kinds of modified asphalt binders had similar $\left|G^{*}\right| / \sin (\delta)$ gap variation with the storage temperature: the $\left|G^{*}\right| / \sin (\delta)$ gap between the top and bottom section was smaller at low storage temperature $\left(120^{\circ} \mathrm{C}\right)$, the $\left|G^{*}\right| / \sin (\delta)$ gap was larger at $163^{\circ} \mathrm{C}$, and the $\left|G^{*}\right| / \sin (\delta)$ gap slightly rose when the storage temperature rose to $175^{\circ} \mathrm{C}$. It can be found that storage temperature had an influence on the storage stability of nanoparticle modified asphalt binders. The storage stability of nanoparticle modified asphalt binders was better at low temperatures than that at high temperatures.

A nanoparticle modified asphalt binder is a dispersed system. The molecular heat motion in the dispersed system of the modified asphalt binders increased with temperature. The agglomerated nanoparticle and micelle composition of heavy asphaltene trended to sink at high storage temperature resulting in $\left|G^{*}\right| / \sin (\delta)$ gap increasing. Consequently, the storage 
stability of nanoparticle modified asphalt binders decreased with storage temperatures.

\section{Analysis of Variance (ANOVA)}

In statistics, analysis of variance (ANOVA) is an important technique to determine whether there is a significant difference between two or more sample means of populations $[25,26]$

To statistically evaluate the effects of nanoparticle size, nanoparticle content, storage time, and storage temperature on the storage stability of nanoparticle modified asphalt binders, one-way ANOVA (single factor) was carried out in this research.

(1) ANOVA of Nanoparticle Size. The one-way ANOVA (single factor) was carried out in this research with $95 \%$ confidence interval ( $\alpha=0.05)$ to determine whether there was a significant difference of the storage stability between $\mathrm{TiO}_{2}-50$ and $\mathrm{TiO}_{2}-100$ groups. The primary variables included softening point, failure temperature, dynamic-shear viscosity, and rutting factor $\left(\left|G^{*}\right| / \sin (\delta)\right)$.

The null hypothesis tested by ANOVA is that the population means for all conditions are the same. The hypotheses for the two-tailed test were as follows.

The Null Hypothesis, $\mathrm{H}_{0}$. The storage stability of the $\mathrm{TiO}_{2}-50$ modified asphalt binder was similar to that of the $\mathrm{TiO}_{2}-100$ modified asphalt binder.

The Proposed Hypothesis, $H_{1}$. The storage stability of $\mathrm{TiO}_{2}-50$ modified asphalt binder was different from that of the $\mathrm{TiO}_{2}$ 100 modified asphalt binder.

If the null hypothesis was rejected as the significance value was smaller than the significance level, $\alpha(0.05)$, then it can be concluded that at least one of the population means was different from at least one other population mean. Therefore, the two populations were found to be statistically significantly different. Table 3 presents the ANOVA between the $\mathrm{TiO}_{2}-50$ and $\mathrm{TiO}_{2}-100$ groups.

From Table 3, the significance value of 0.736 in softening point was larger than $\alpha$ (0.05); thus the proposed hypothesis was rejected and it indicated that there was no significant difference of the storage stability between $\mathrm{TiO}_{2}-50$ and $\mathrm{TiO}_{2}-$ 100 groups according to the softening point.

Correspondingly, it can be seen from Table 3 that the significance value of 0.890 in failure temperature, the significance value of 0.711 in dynamic-shear viscosity, and the significance value of 0.668 in rutting factor were larger than $\alpha$ (0.05). The one-way ANOVA with single factor showed that there was no statistically significant difference of the storage stability between $\mathrm{TiO}_{2}-50$ and $\mathrm{TiO}_{2}-100$ groups based on the indexes of failure temperature, viscosity, and rutting factor.

The test of one-way ANOVA indicated that the nanoparticle size had no significant influence on the storage stability of nanoparticle modified asphalt binders, which could be mainly due to the fact that the agglomeration of nanoparticle reduced the dispersion of nanoparticle in the dispersed system of modified asphalt binder and the difference of size effects for nanoparticle on the storage stability. The StokesEinstein equation provides an estimate of the terminal velocity of a particle in a dispersed system [27]:

$$
v_{s}=\frac{d^{2} \Delta \rho g}{18 \eta_{c}},
$$

where $v_{s}$ is the terminal velocity, $d$ is the particle diameter, $\Delta \rho$ is the density difference between dispersed phase and continuous phase, $g$ is the gravitational acceleration, and $\eta_{c}$ is the continuous phase viscosity.

From Figure 1, the agglomeration of $\mathrm{TiO}_{2}-50$ is more obvious than that of $\mathrm{TiO}_{2}-100$. The agglomeration of $\mathrm{TiO}_{2}$ 50 will escalate in the dispersed system of modified asphalt binder to further increase the terminal velocity of the agglomerated particles to sink. Therefore, reducing the nanoparticle size cannot effectively enhance the storage stability of nanoparticle modified asphalt binders, but improving the dispersion of nanoparticle was thought to be a positive method.

(2) ANOVA of Nanoparticle Content. To analyze the effects of nanoparticle content on the storage stability of nanoparticle modified asphalt binders, the one-way ANOVA was also employed. The hypotheses for the two-tailed test were as follows.

The Null Hypothesis, $H_{0}$. The storage stability of the modified asphalt binders was the same in the conditions of different nanoparticle content.

The Proposed Hypothesis, $H_{1}$. The storage stability of modified asphalt binder was different in the conditions of different nanoparticle content.

Tables 4-7 present the variance analysis of softening point, failure temperature, viscosity, and rutting factor between the groups of different nanoparticle contents.

As shown in Table 4, the results of the ANOVA indicated that the significance value of 0.020 in softening point was less than the significance level, $\alpha=0.05$; therefore, it can be concluded that there was enough evidence to suggest a difference between the groups of different nanoparticle contents. It can be found that there is a significant difference between the groups of different nanoparticle contents in the softening point value.

According to one-way ANOVA in Tables 5-7, it suggested that there were significant differences in failure temperature, viscosity, and rutting factor between the groups of different nanoparticle contents, which was further verification of the effects of nanoparticle content on the storage stability of nanoparticle modified asphalt binders.

The test of one-way ANOVA with single factor showed that there was a statistically significant difference between the groups of different nanoparticle contents. It could be learnt that the nanoparticle content of $0.50 \% \sim 2.50 \%$ had a significant influence on the storage stability of asphalt binders based on the ANOVA. 
TABLE 3: ANOVA: single factor between the $\mathrm{TiO}_{2}-50$ and $\mathrm{TiO}_{2}-100$ groups.

\begin{tabular}{|c|c|c|c|c|c|c|c|}
\hline Properties & Source of & ariation & Sum of squares & Degree of freedom & Mean Square & $F$ & Significance \\
\hline \multirow{4}{*}{ Softening point } & \multirow{2}{*}{ Between groups } & (Combined) & 0.016 & 1 & 0.016 & 0.122 & 0.736 \\
\hline & & Linear term & 0.016 & 1 & 0.016 & 0.122 & 0.736 \\
\hline & \multicolumn{2}{|c|}{ Within groups } & 1.048 & 8 & 0.131 & & \\
\hline & \multicolumn{2}{|c|}{ Total } & 1.064 & 9 & & & \\
\hline \multirow{4}{*}{ Failure temperature } & \multirow{2}{*}{ Between groups } & (Combined) & 0.008 & 1 & 0.008 & 0.020 & 0.890 \\
\hline & & Linear term & 0.008 & 1 & 0.008 & 0.020 & 0.890 \\
\hline & \multicolumn{2}{|c|}{ Within groups } & 3.092 & 8 & 0.386 & & \\
\hline & \multicolumn{2}{|c|}{ Total } & 3.100 & 9 & & & \\
\hline \multirow{4}{*}{ Dynamic shear viscosity } & \multirow{2}{*}{ Between groups } & (Combined) & 1.600 & 1 & 1.600 & 0.147 & 0.711 \\
\hline & & Linear term & 1.600 & 1 & 1.600 & 0.147 & 0.711 \\
\hline & \multicolumn{2}{|c|}{ Within groups } & 87.016 & 8 & 10.877 & & \\
\hline & \multicolumn{2}{|c|}{ Total } & 88.616 & 9 & & & \\
\hline \multirow{4}{*}{ Rutting factor } & \multirow{2}{*}{ Between groups } & (Combined) & 16.900 & 1 & 16.900 & 0.198 & 0.668 \\
\hline & & Linear term & 16.900 & 1 & 16.900 & 0.198 & 0.668 \\
\hline & \multicolumn{2}{|c|}{ Within groups } & 681.200 & 8 & 85.150 & & \\
\hline & \multicolumn{2}{|c|}{ Total } & 698.100 & 9 & & & \\
\hline
\end{tabular}

TABLE 4: ANOVA: single factor between the groups of different particle contents on softening point value.

\begin{tabular}{|c|c|c|c|c|c|c|c|}
\hline \multicolumn{3}{|l|}{ Source of variation } & Sum of squares & Degree of freedom & Mean square & $F$ & Significance \\
\hline \multirow{3}{*}{ Between groups } & \multicolumn{2}{|c|}{ (Combined) } & 0.924 & 4 & 0.231 & 8.250 & 0.020 \\
\hline & \multirow{2}{*}{ Linear term } & Contrast & 0.761 & 1 & 0.761 & 27.161 & 0.003 \\
\hline & & Deviation & 0.163 & 3 & 0.054 & 1.946 & 0.240 \\
\hline Within groups & & & 0.140 & 5 & 0.028 & & \\
\hline Total & & & 1.064 & 9 & & & \\
\hline
\end{tabular}

TABLE 5: ANOVA: single factor between the groups of different particle contents on failure temperature.

\begin{tabular}{|c|c|c|c|c|c|c|c|}
\hline \multicolumn{3}{|l|}{ Source of variation } & Sum of squares & Degree of freedom & Mean square & $F$ & Significance \\
\hline \multirow{3}{*}{ Between groups } & \multicolumn{2}{|c|}{ (Combined) } & 3.024 & 4 & 0.756 & 50.205 & 0 \\
\hline & \multirow{2}{*}{ Linear term } & Contrast & 2.957 & 1 & 2.957 & 196.335 & 0 \\
\hline & & Deviation & 0.068 & 3 & 0.023 & 1.495 & 0.323 \\
\hline Within groups & & & 0.075 & 5 & 0.015 & & \\
\hline Total & & & 3.100 & 9 & & & \\
\hline
\end{tabular}

TABLE 6: ANOVA: single factor between the groups of different particle contents on viscosity.

\begin{tabular}{|c|c|c|c|c|c|c|c|}
\hline Source of variatic & & & Sum of squares & Degree of freedom & Mean square & $F$ & Significance \\
\hline \multirow{3}{*}{ Between groups } & \multicolumn{2}{|c|}{ (Combined) } & 80.616 & 4 & 20.154 & 12.596 & 0.008 \\
\hline & \multirow{2}{*}{ Linear term } & Contrast & 75.272 & 1 & 75.272 & 47.045 & 0.001 \\
\hline & & Deviation & 5.344 & 3 & 1.781 & 1.113 & 0.426 \\
\hline \multicolumn{3}{|l|}{ Within groups } & 8.000 & 5 & 1.600 & & \\
\hline \multicolumn{3}{|l|}{ Total } & 88.616 & 9 & & & \\
\hline
\end{tabular}

TABLE 7: ANOVA: single factor between the groups of different particle contents on rutting factor.

\begin{tabular}{|c|c|c|c|c|c|c|c|}
\hline \multicolumn{3}{|l|}{ Source of variation } & \multirow{2}{*}{$\begin{array}{c}\text { Sum of squares } \\
657.600\end{array}$} & \multirow{2}{*}{$\frac{\text { Degree of freedom }}{4}$} & \multirow{2}{*}{$\begin{array}{c}\text { Mean square } \\
164.400\end{array}$} & \multirow{2}{*}{\begin{tabular}{c|}
$F$ \\
20.296
\end{tabular}} & \multirow{2}{*}{$\begin{array}{c}\text { Significance } \\
0.003\end{array}$} \\
\hline \multirow{3}{*}{ Between groups } & (Con & hed) & & & & & \\
\hline & \multirow{2}{*}{ Linear term } & Contrast & 520.200 & 1 & 520.200 & 64.222 & 0 \\
\hline & & Deviation & 137.400 & 3 & 45.800 & 5.654 & 0.046 \\
\hline Within groups & & & 40.500 & 5 & 8.100 & & \\
\hline Total & & & 698.100 & 9 & & & \\
\hline
\end{tabular}


TABLE 8: ANOVA: single factor between the groups of different storage time on rutting factor.

\begin{tabular}{|c|c|c|c|c|c|c|c|}
\hline \multicolumn{3}{|l|}{ Source of variation } & \multirow{2}{*}{$\begin{array}{c}\text { Sum of squares } \\
3659.750\end{array}$} & \multirow{2}{*}{$\frac{\text { Degree of freedom }}{5}$} & \multirow{2}{*}{$\begin{array}{c}\text { Mean square } \\
731.950\end{array}$} & \multirow{2}{*}{$\begin{array}{c}F \\
14.236\end{array}$} & \multirow{2}{*}{$\frac{\text { Significance }}{0.003}$} \\
\hline \multirow{3}{*}{ Between groups } & (Com & ed) & & & & & \\
\hline & \multirow{2}{*}{ Linear term } & Contrast & 3177.779 & 1 & 3177.779 & 61.804 & 0 \\
\hline & & Deviation & 481.971 & 4 & 120.493 & 2.343 & 0.168 \\
\hline Within groups & & & 308.500 & 6 & 51.417 & & \\
\hline Total & & & 3968.250 & 11 & & & \\
\hline
\end{tabular}

TABLE 9: ANOVA: single factor between the groups of different storage temperatures on rutting factor.

\begin{tabular}{|c|c|c|c|c|c|c|c|}
\hline \multicolumn{3}{|c|}{ Source of variation } & \multirow{2}{*}{$\begin{array}{c}\text { Sum of squares } \\
3493.000\end{array}$} & \multirow{2}{*}{$\frac{\text { Degree of freedom }}{2}$} & \multirow{2}{*}{$\begin{array}{c}\text { Mean square } \\
1746.500\end{array}$} & \multirow{2}{*}{$\frac{F}{499.000}$} & \multirow{2}{*}{$\frac{\text { Significance }}{0}$} \\
\hline \multirow{3}{*}{ Between groups } & (Com & hed) & & & & & \\
\hline & \multirow{2}{*}{ Linear term } & Contrast & 2862.250 & 1 & 2862.250 & 817.786 & 0 \\
\hline & & Deviation & 630.750 & 1 & 630.750 & 180.214 & 0.001 \\
\hline Within groups & & & 10.500 & 3 & 3.500 & & \\
\hline Total & & & 3503.500 & 5 & & & \\
\hline
\end{tabular}

(3) ANOVA of Storage Time. The test of ANOVA of the rutting factors between the groups of different storage time was applied to investigate the effect of storage time on the storage stability of nanoparticle modified asphalt binders. The hypotheses for the two-tailed test are as follows.

The Null Hypothesis, $H_{0}$. The storage stability of the modified asphalt binders was the same in the conditions of different storage time.

The Proposed Hypothesis, $H_{1}$. The storage stability of modified asphalt binder was different in the conditions of different storage time.

The results of ANOVA between the groups of different storage time on rutting factor are shown in Table 8 . The results showed that the significance value of 0.03 was less than $\alpha(0.05)$. The null hypothesis was rejected; thus, it can be concluded that there was a significant difference between the groups of different storage time concerning the rutting factors.

The ANOVA indicated that storage time had a significant influence on storage stability of nanoparticle modified asphalt binders.

(4) ANOVA of Storage Temperature. The test of ANOVA on rutting factor between the groups of different storage temperature was applied to investigate the effect of storage temperature on the storage stability of nanoparticle modified asphalt binder. The hypotheses for the two-tailed test were as follows.

The Null Hypothesis, $H_{0}$. The storage stability of the modified asphalt binders was the same in the conditions of different storage temperature.

The Proposed Hypothesis, $H_{1}$. The storage stability of modified asphalt binder was different in the conditions of different storage temperature.
The results of ANOVA between the groups of different storage temperatures on rutting factor are shown in Table 9. The significance value was less than $\alpha(0.05)$. The null hypothesis was rejected, so it can be concluded that there was a significant difference between the groups of different storage time. The results indicated that storage temperature had a significant influence on the storage stability of nanoparticle modified asphalt binders.

The results of ANOVA further verified the previous analysis of the tests on the modified asphalt binders. In order to improve the storage stability of nanoparticle modified asphalt binders, proper nanoparticle contents, lower storage time, and temperatures can be chosen. At the same time, it is important to improve the dispersion of nanoparticle modified asphalt binders.

\section{Conclusions}

This study adopted the hot tube storage test, the softening point test, and the DSR test to investigate the storage stability of the nano- $\mathrm{TiO}_{2}$ modified asphalt with the variation of nanoparticle content, storage time, and storage temperature. Based on the results and the ANOVA, the following conclusions can be drawn:

(a) The storage stability of nanoparticle modified asphalt binders decreased with the nanoparticle content.

(b) The storage time had an impact on storage stability of nanoparticle modified asphalt binders and the impact was remarkable when the storage time was more than $48 \mathrm{~h}$. It is necessary to take measures to improve the storage stability of nanoparticle modified asphalt binders when the storage time was more than $48 \mathrm{~h}$.

(c) The storage stability of nanoparticle modified asphalt binders at low temperatures was better than that at high temperatures.

(d) Reducing the nanoparticle size cannot effectively enhance the storage stability of the nanoparticle 
modified asphalt binder due to the agglomeration of nanoparticle.

\section{Disclosure}

The results and opinions presented are those of the authors and do not necessarily reflect those of the sponsoring agencies.

\section{Conflicts of Interest}

The authors declare that they have no conflicts of interest.

\section{Authors' Contributions}

Xiaolong Zou and Aimin Sha conceived and designed the experiments; Xiaolong Zou, Yuqiao Tan, and Xiaonan Huang performed the experiments; Xiaolong Zou wrote the paper; Xiaolong Zou and Biao Ding analyzed the data.

\section{Acknowledgments}

This research was sponsored by the Ministry of Science and Technology of China (2014BAG05B04), the Ph.D. Research Startup Foundation of Xian University of Science and Technology (2017QDJ024), the opening fund of Guangxi Key Lab of Road Structure and Materials (2017gxjgclkf-001), and the Natural Science Foundation of Shaanxi Province (2016JQ5115). The authors would also like to thank Mr. Hao Liu for his contribution to this research.

\section{References}

[1] A. N. Amirkhanian, F. Xiao, and S. N. Amirkhanian, "Characterization of unaged asphalt binder modified with carbon nano particles," International Journal of Pavement Research and Technology, vol. 4, no. 5, pp. 281-286, 2011.

[2] S. W. Goh, M. Akin, Z. You, and X. Shi, "Effect of deicing solutions on the tensile strength of micro- or nano-modified asphalt mixture," Construction and Building Materials, vol. 25, no. 1, pp. 195-200, 2011.

[3] J. Yang and S. Tighe, "A review of advances of nanotechnology in asphalt mixtures," Procedia - Social and Behavioral Sciences, vol. 96, pp. 1269-1276, 2013.

[4] T. F. Pamplona, B. De C. Amoni, A. E. V. De Alencar et al., "Asphalt binders modified by SBS and SBS/nanoclays: Effect on rheological properties," Journal of the Brazilian Chemical Society, vol. 23, no. 4, pp. 639-647, 2012.

[5] M. V. De Ven, A. Molenaar, J. Besamusca, and J. Noordergraaf, "Nanotechnology for binders of asphalt mixtures," in Proceedings of the 4th Eurasphalt and Eurobitume Congress, Copenhagen, Denmark, 2008.

[6] B. Golestani, F. Moghadas Nejad, and S. Sadeghpour Galooyak, "Performance evaluation of linear and nonlinear nanocomposite modified asphalts," Construction and Building Materials, vol. 35, pp. 197-203, 2012.

[7] B. Golestani, B. H. Nam, F. Moghadas Nejad, and S. Fallah, "Nanoclay application to asphalt concrete: Characterization of polymer and linear nanocomposite-modified asphalt binder and mixture," Construction and Building Materials, vol. 91, pp. 32-38, 2015.

[8] M. Ameri, S. Nobakht, K. Bemana, H. Rooholamini, and M. Vamegh, "Effect of nanoclay on fatigue life of hot mix asphalt," Petroleum Science and Technology, vol. 34, no. 11-12, pp. 10211025, 2016.

[9] S. G. Jahromi and A. Khodaii, "Effects of nanoclay on rheological properties of bitumen binder," Construction and Building Materials, vol. 23, no. 8, pp. 2894-2904, 2009.

[10] L. G. A. T. Farias, J. L. Leitinho, B. D. C. Amoni et al., "Effects of nanoclay and nanocomposites on bitumen rheological properties," Construction and Building Materials, vol. 125, pp. 873-883, 2016.

[11] G. Mojtaba, M. S. Morteza, T. Majid, K. R. Jalal, and T. Reza, "Modification of stone matrix asphalt with nano- $\mathrm{SiO}_{2}$," Journal of Basic and Applied Scientific Research, vol. 2, no. 2, pp. 13381344, 2012.

[12] L. Mohammad, M. Hassan, and S. Cooper III, "Mechanical characteristics of asphaltic mixtures containing titaniumdioxide photocatalyst," Journal of Testing and Evaluation, vol. 40, no. 6, pp. 1-8, 2012.

[13] A. Beeldens, "An environmental friendly solution for air purification and self-cleaning effect: the application of $\mathrm{TiO}_{2}$ as photocatalyst in concrete," in Proceedings of the Transport Research Arena Europe-TRA, Göteborg, Sweden, 2006.

[14] M. M. Hassan, H. Dylla, L. N. Mohammad, and T. Rupnow, "Evaluation of the durability of titanium dioxide photocatalyst coating for concrete pavement," Construction and Building Materials, vol. 24, no. 8, pp. 1456-1461, 2010.

[15] J. Tanzadeh, F. Vahedi, T. K. Pezhouhan, and R. Tanzadeh, "Laboratory study on the effect of nano Tio2 on rutting performance of asphalt pavements," Advanced Materials Research, vol. 622, pp. 990-994, 2013.

[16] G. Shafabakhsh, S. M. Mirabdolazimi, and M. Sadeghnejad, "Evaluation the effect of nano-TiO2 on the rutting and fatigue behavior of asphalt mixtures," Construction and Building Materials, vol. 54, pp. 566-571, 2014.

[17] P. Xiao and X. Li, "Research on the performance and mechanism of nanometer $\mathrm{ZnO} / \mathrm{SBS}$ modified asphalt," Journal of Highway and Transportation Research and Development, vol. 24, no. 6, pp. 12-16, 2007.

[18] M. M. Hassan, L. N. Mohammad, S. B. Cooper, and H. Dylla, "Evaluation of nano-titanium dioxide additive on asphalt binder aging properties," Transportation Research Record, no. 2207, pp. 11-15, 2011

[19] C. Ouyang, S. Wang, Y. Zhang, and Y. Zhang, "Thermorheological properties and storage stability of SEBS/kaolinite clay compound modified asphalts," European Polymer Journal, vol. 42, no. 2, pp. 446-457, 2006.

[20] H. U. Bahia and H. Zhai, "Storage stability of modified binders using the newly developed LAST procedure," Road Materials and Pavement Design, vol. 1, no. 1-2, pp. 53-73, 2000.

[21] Y. Niu, Z. Zhu, J. Xiao, Z. Liu, and B. Liang, "Evaluation of storage stability of styrene-butadiene-styrene block copolymermodified asphalt via electrochemical analysis," Construction and Building Materials, vol. 107, pp. 38-43, 2016.

[22] H. Fu, L. Xie, D. Dou, L. Li, M. Yu, and S. Yao, "Storage stability and compatibility of asphalt binder modified by SBS graft copolymer," Construction and Building Materials, vol. 21, no. 7, pp. 1528-1533, 2007. 
[23] P. F. Luckham and M. A. Ukeje, "Effect of particle size distribution on the rheology of dispersed systems," Journal of Colloid and Interface Science, vol. 220, no. 2, pp. 347-356, 1999.

[24] X. Zou, A. Sha, W. Jiang, and X. Huang, "Modification mechanism of high modulus asphalt binders and mixtures performance evaluation," Construction and Building Materials, vol. 90, pp. 53-58, 2015.

[25] B. G. Tabachnick and L. S. Fidell, Using Multivariate Statistics, Allyn \& Bacon, 5th edition, 2006.

[26] H. Asli, E. Ahmadinia, M. Zargar, and M. R. Karim, "Investigation on physical properties of waste cooking oil - Rejuvenated bitumen binder," Construction and Building Materials, vol. 37, pp. 398-405, 2012.

[27] D. D. Li and M. L. Greenfield, "Viscosity, relaxation time, and dynamics within a model asphalt of larger molecules," The Journal of Chemical Physics, vol. 140, no. 3, article 034507, 2014. 

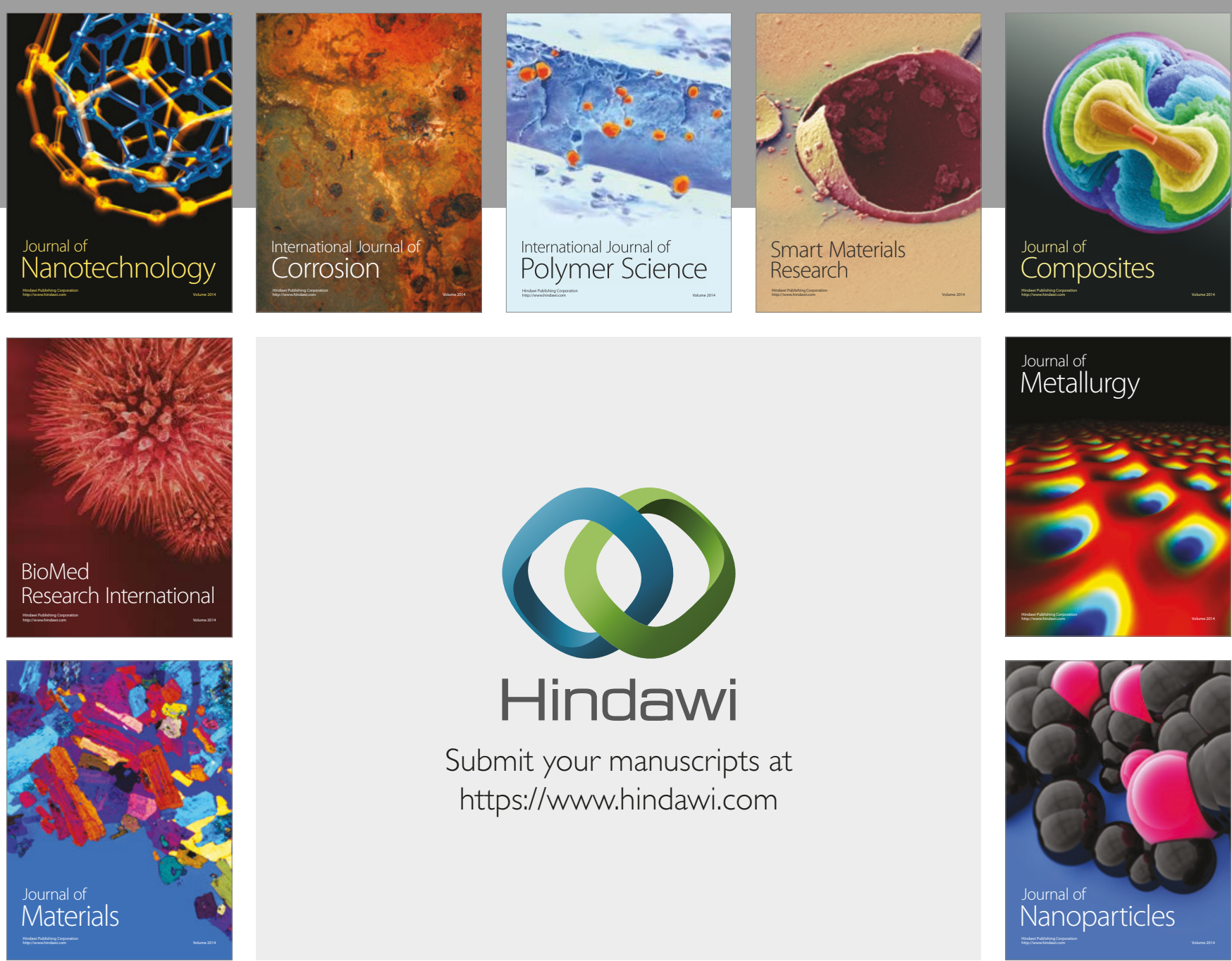

\section{Hindawi}

Submit your manuscripts at

https://www.hindawi.com
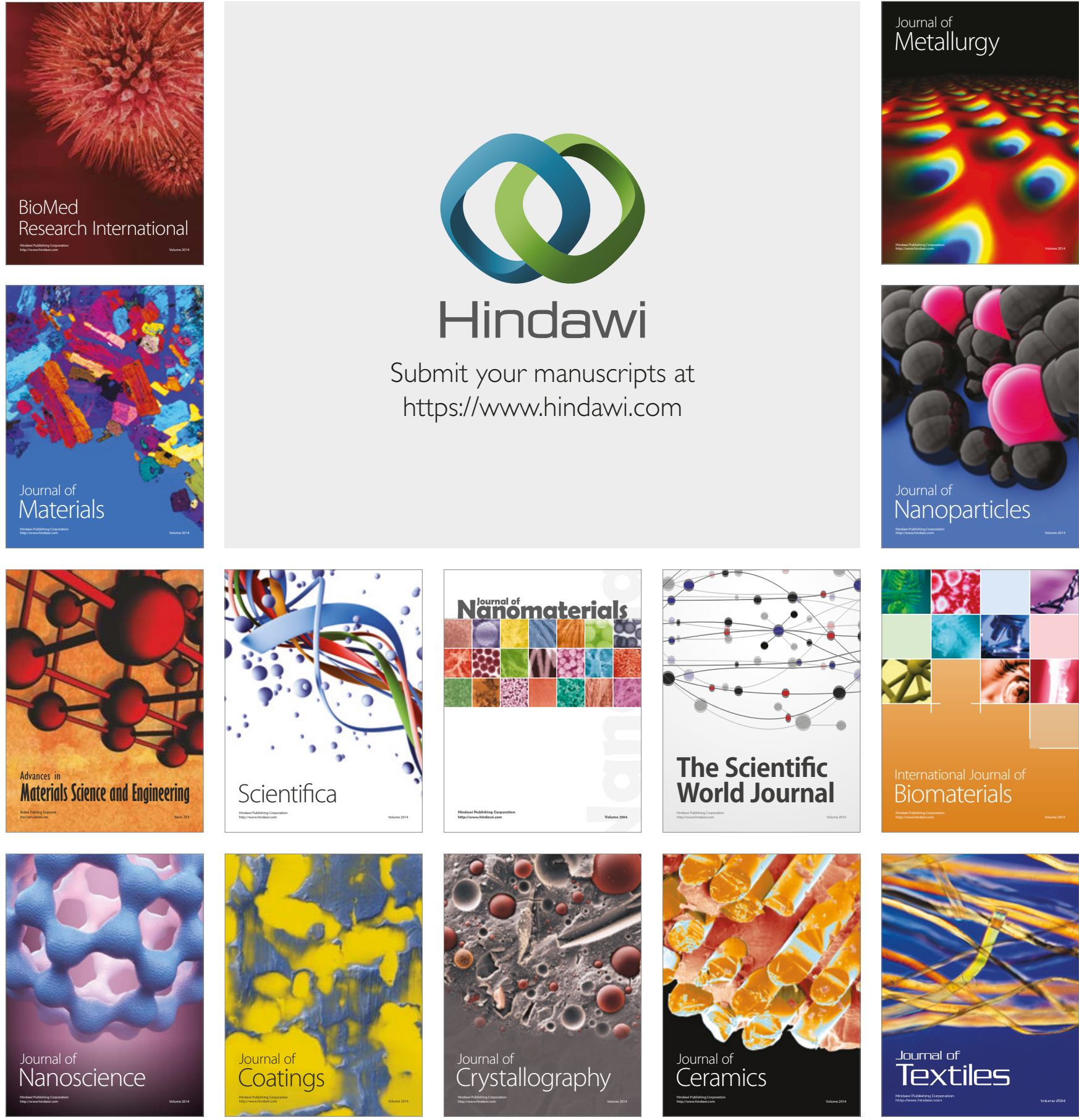

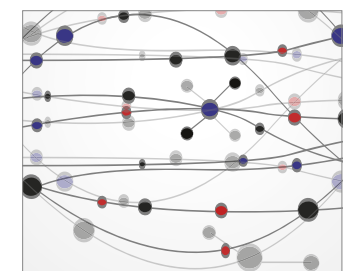

The Scientific World Journal
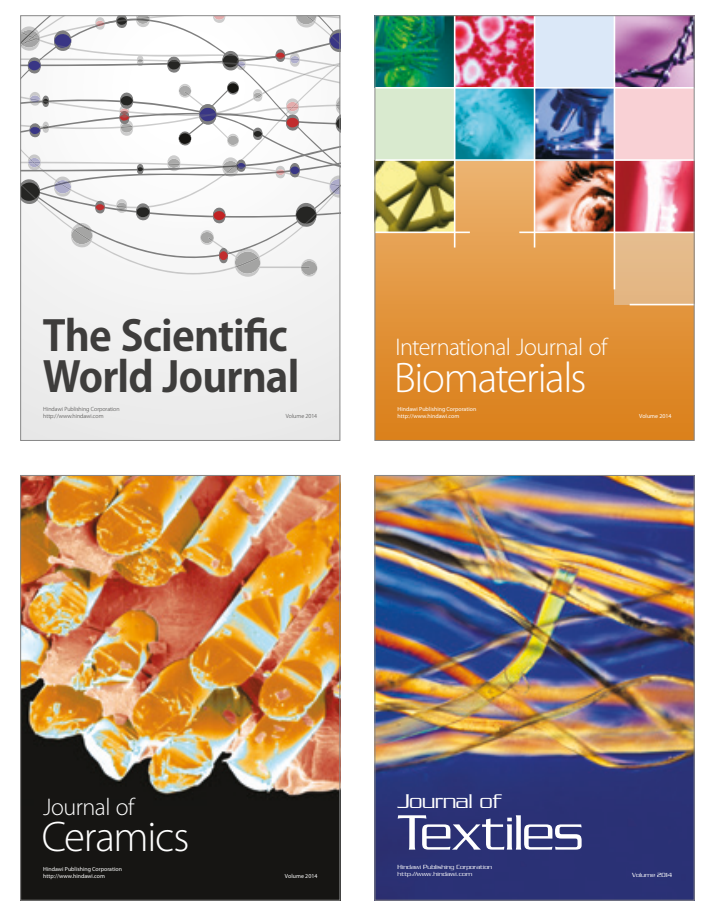